\title{
SPT 垂直ライトヘッドにおける反強磁性結合多層膜の膜構成最適化検討
}

\author{
Optimum Layer Structure of Antiferromagnetic-Coupled Multilayer \\ for SPT Perpendicular Writer Heads
}

\author{
秋元秀行・清水香壱* ${ }^{*}$ 金井 均・田村 亮* ・池川幸徳・上原裕二 \\ 富士通株式会社 ヘッド先行開発部，長野県長野市北尾張部 36（テ381-8501） \\ "富士通株式会社 物理シミュレーション技術部，神奈川県川崎市中原区上小田中 4-1-1（勇211-8588）
}

H. Akimoto, K. Shimizu*, H. Kanai, A. Tamura*, Y. Ikegawa, and Y. Uehara

Advance Head Technology Department, Fujitsu Ltd., 36 Kita-owaribe, Nagano, 381-8501, Japan

*Physical Simulation Technology Department, Fujitsu Ltd., 4-1-1 Kamikodanaka, Nakahara-ku, Kawasaki, 211-8588, Japan

\begin{abstract}
Perpendicular magnetic recording using a single-poletype (SPT) writer head and a double-layer perpendicular medium with a soft underlayer (SUL) has several advantages for high-density magnetic recording. It is therefore a promising candidate for a next-generation magnetic recording system. However, the pole-erase phenomenon, which is a signal reduction caused by a remanent head field from the main pole, prevents high-density recording. We investigated an SPT writer head with antiferromagnetic- (AFM-) coupled main pole to avoid the pole-erase phenomenon by using recently developed combined micromagnetics and finite-element method simulations. We demonstrated that the recording head field decreases monotonically with increasing number of AFM-coupled layers. On the other hand, residual field (pole-erase field) strength dramatically decreases to around half while applying an AFM-coupled bi-layer for the main pole. The pole-erase field is almost constant in the case of two or more layers. The optimum layer number of an AFM-coupled multilayer for the main pole is from two to four layers from the recording and pole-erase field point of view. We confirmed the same tendency by experimental observation of the pole-erase.
\end{abstract}

Key words: SPT perpendicular writer head, antiferromagnetic coupling, multilayer, pole-erase, LLG, FEM, simulations.

\section{1. はじめに}

軟磁性裏打ち層(SUL)を有する二層垂直磁気記録媒体と単磁極 (SPT)ライトヘッドとの組合せからなる垂直磁気記録は高い分解能 が得られること，高面記録密度において反磁界が小さくなり而熱 ゆらぎ性に優れることなどの様々な利点を持つことから次世代の 磁気記録方式として期待されている1)-3). 一方で, 垂直磁気記録特 有の問題点もくつか報告されている4), 5). 例えば, 記録電流才フ後 もへッド主磁極に残留磁化が残り媒体上の磁気記録情報を消して しまうポールイレーズ現象出が指摘されている. ポールイレーズ対 策として, 主磁極の強磁性体を非磁生層で分断した構造6)や Ru 層 を介して反強磁結合させる構造7などが提案されている. また，ポ 一ルイレーズの解析としてマイクロマグネティックス(LLG)を用 いた計算機シミュレーション結果が報告されている8),9)が, 現在の ヘッドサイズ全体をモデル化するに至っていない。一方シミュレ ーションを用いたヘッド構造に対する発生磁界の解析も行われて いるが, 有限要素法(FEM)を用いている場合がほとんどであり10),
11), 残留磁界強度の解析や主磁極の多層膜構造をモデル化するに は適していない。本論文ではLLG と FEM を組み合わせたシミュ レータを新たに開発し，ポールイレーズ対策として反強磁性結合 多層膜を主磁極材料として適用した場合の記録・残留磁界の解析 を行った。また, その膜構成の最適化について検討した結果につ いて報告する。

\section{2. 計算方法}

多層膜主磁極のモデル化, 残留磁界の計算を行うにあたり, LLG と FEM を組み合わせたシミュレータを新たに開発した ${ }^{12)}$. 計算 に使用する基礎方程式は Landau-Lifshitz-Gilbert 方程式(1)と磁 場の方程式(2)または(3)である.

$$
\begin{aligned}
& \frac{\partial \vec{m}}{\partial t}=-\gamma\left(\vec{m} \times \vec{H}_{e f f}\right)-\alpha\left(\vec{m} \times \frac{\partial \vec{m}}{\partial t}\right) \\
& \vec{\nabla} \times\left(\frac{1}{\mu_{0}} \vec{\nabla} \times \vec{A}\right)=\vec{J}_{0}+\frac{1}{\mu_{0}} \vec{\nabla} \times M_{s} \cdot \vec{m} \\
& \vec{\nabla} \times\left(\frac{1}{\mu} \vec{\nabla} \times \vec{A}\right)=\vec{J}_{0}
\end{aligned}
$$

上式において $M_{S}, \vec{m}, \gamma, \alpha$ は飽和磁化密度, 磁化方向を示寸単 位ベクトル, ジャイロ磁気定数, 減衰定数である. また, $\mu 0, \mu$, J0, $\vec{A}$ はそれぞれ真空の透磁率, 透磁率, 強制電流密度, 磁気心゙ クトルポテンシャルである. なお, 式(1)の $\vec{H}_{e f f}$ は LLG 計算領域 における各計算セルに加わる実効的な印加磁界で, 次式により算 出される.

$$
\vec{H}_{e f f}=\frac{1}{\mu_{0}}\left(\vec{\nabla} \times \vec{A}-M_{s} \cdot \vec{m}\right)+\vec{H}_{e x}+\vec{H}_{k}
$$

ここで $\vec{H}_{e x}, \vec{H}_{k}$ はそれぞれ交換磁気結合磁界, 結晶磁気異方性 磁界である.

モデル内ではLLG 方程式は有限体積法で, 磁場の方程式は辺要 素を用いた有限要素法で離散化した. 磁場の方程式は, LLGとし て磁化が定義されている領域を式(2)により, 空気領域を含め磁生 体を透磁率で指定する領域(FEM領域)を式(3)でそれぞれ計算して いる. なお，LLG 領域においてはセル内の磁気モーメントの大き さは一定とし, その方向のみが変化するものとして計算を行った. 


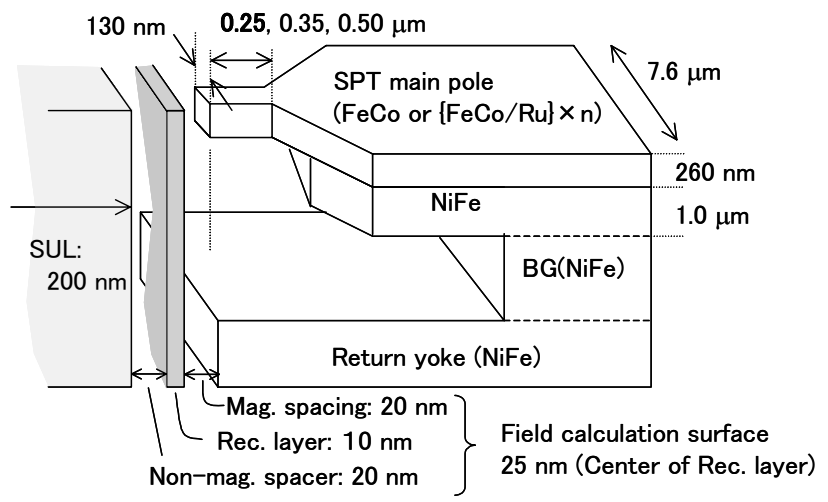

Fig.1 Schematic calculation model of STP perpendicular writer head.

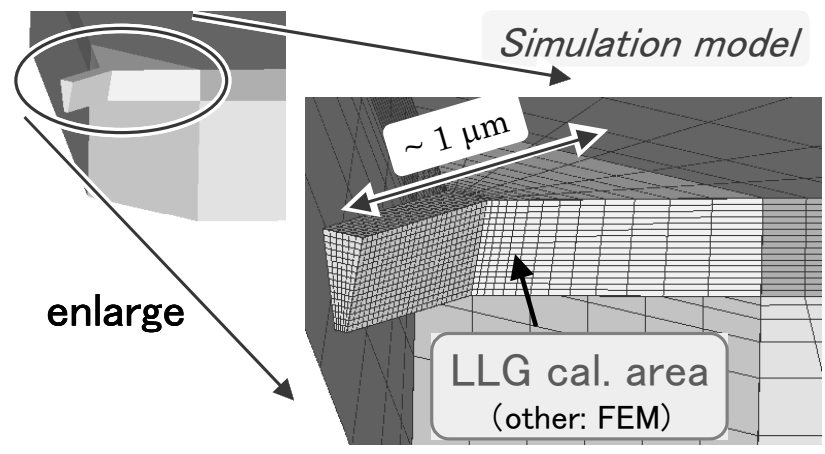

Fig. 2 LLG + FEM model of STP writer head. The figure shows the structure and the LLG, FEM calculation area at the near air-bearing surface.

\section{3. 計算パラメータ}

本論文で使用した SPT 垂直ライトヘッドのモデルを Fig. 1 に示 す. 主磁極はトレーリング側の光学コア幅 $130 \mathrm{~nm}$, 膜厚 $260 \mathrm{~nm}$ 一定とし，その浮上面形状はトレーリング側のコア幅が広いトリ ム角 10 度の逆台形形状を仮定した. また記録へッドに加え軟磁性 裏打ち層(SUL)についてもモデル化を行った. なお，記録層につい ては空気領域として扱い，記録層中心における各ヘッドの記録・ 残留磁界強度をシミュレーションにより算出した，具体的には主 磁極と SUL との間隔を $50 \mathrm{~nm}$ とし，記録層中心として主磁極か ら $25 \mathrm{~nm}$ 位置における二次元平面の磁界分布を算出した. ヘッド からの発生磁界は面内成分を含めた三次元計算を行っているが, 本論文では垂直成分に限定し解析を行った. Fig. 2 は計算に用いた 主磁極先端部のメッシュ構造およびLLG/FEM 計算領域の一例で ある. LLG 計算領域は主磁極ヨーク部の磁化状態を反映させるの に必要十分な奥行として $1.0 \mu \mathrm{m}$ を設定した。一方 SULを含む他 の部分については FEM 計算領域としてモデル化した. 全体のモ デル規模としては約 10 万節点, LLG 計算領域として約 5000 要素 である.

次に反強磁性結合を有する多層膜主磁極のモデル化方法につい て説明する．膜厚 $260 \mathrm{~nm} の$ 主磁極を膜厚方向に 24 要素(約 10.8 $\mathrm{nm}$ )に等分割し,膜厚方向の各要素間の交換磁気結合力を正および 負に設定することでメッシュ構造を変えることなく多層膜構造を 表現した. 例えば 4 層多層膜は $\mathrm{Ru}$ の存在しない 6 要素間(膜厚: 65
Table 1 Simulated write and residual magnetic field strength of different $T H$ SPT writer heads.

\begin{tabular}{|c|c|c|c|}
\hline \multirow{2}{*}{} & \multicolumn{3}{|c|}{ Throat heights $(T H)$} \\
\cline { 2 - 4 } & $0.25 \mu \mathrm{m}$ & $0.35 \mu \mathrm{m}$ & $0.50 \mu \mathrm{m}$ \\
\hline Recording field & $8890 \mathrm{Oe}$ & $8290 \mathrm{Oe}$ & $7640 \mathrm{Oe}$ \\
\hline Residual field & $1890 \mathrm{Oe}$ & $1230 \mathrm{Oe}$ & $3180 \mathrm{Oe}$ \\
\hline
\end{tabular}

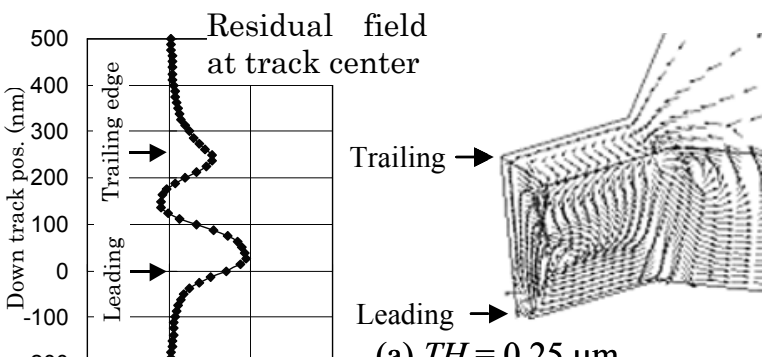

(a) $T H=0.25 \mu \mathrm{m}$
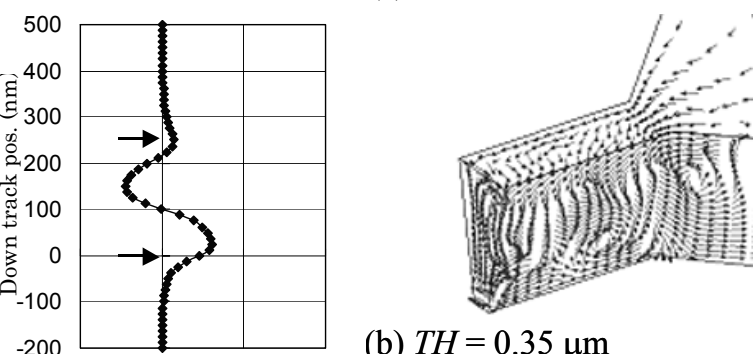

(b) $T H=0.35 \mu \mathrm{m}$
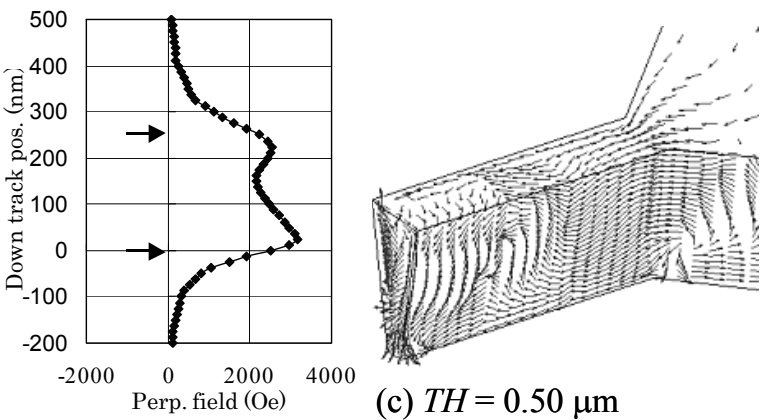

Fig.3 Magnetization configuration of main pole at residual state for different throat height.

$\mathrm{nm})$ に正, $\mathrm{Ru}$ 層が存在する要素間に負の交換磁気結合を交互に与 えることでモデル化した. このため幾何学モデル上は Ru 層に相当 する非磁生層は存在せず，交換磁気結合力の違いとしてのみモデ ル化されている. この時、正の交換結合磁界 $\left(H_{e x}\right)$ は軟磁生膜の典 型的な交換スティフネス定数: $\mathrm{A}=1.0 \times 10^{6} \mathrm{erg} / \mathrm{cm}$ に相当する $1050 \mathrm{Oe}$ を、負の $H_{e x}$ は $\mathrm{FeCo} / \mathrm{Ru}$ 多層膜の実測值である-900 Oe をそれぞれ用いた。主磁極材料の磁気特性としては $B_{S}: 2.4 \mathrm{~T}, H_{k}$ : 50 Oe を仮定した. FEM 領域については $\mu$. 1000 として扱った.

\section{4. シミュレーション結果および考察}

\section{1 単層主磁極のスロートハイト依存性}

初めに主磁極として単層磁生膜を用いた SPT 垂直ライトヘッド の記録磁界およひ残留磁界強度のスロートハイト $(T H)$ 依存性につ いて議論する. 磁界強度の計算は先ず全ての磁化をコア幅方向に 完全に揃えた初期磁化状態から磁化安定点を求めた. その後記録 
電流として $0.15 \mathrm{AT}$ の起磁力を与え記録磁界分布を求め, その分 布から記録磁界強度としてトレーリング側のトラック中心におけ る磁界強度を求めた. 更に, 残留磁界分布として起磁力をゼロに 戻し主磁極が残留磁化状態にある時の磁界分布を算出した. 残留 磁界強度は計算領域内の最大磁界強度を絶対值として算出した.

Table. 1 にシミュレーションにより求めた各 $T H$ における磁界強 度を示した. また Fig. 3 には各ヘッドの残留磁化分布およびトラ ック センターにおける磁界強度のダウトラック位置に対する変 化を示した. $T H$ を縮小寸ることで記録磁界強度はほぼ単調に増加 する.一方残留磁界強度は $T H: 0.35 \mu \mathrm{m}$ を最小とし $0.50,0.25 \mu \mathrm{m}$ いずれの值としても増加する傾向が見られた. 残留磁化は非常に 複雑な分布をしており解釈が困難であるが $T H$ を $0.50 \mu \mathrm{m}$ と大き くした場合, 主磁極先端の形状異方性から磁化が全体としてスロ 一トハイト方向に揃い残留磁界強度が大きくなっているものと 思われる. 一方, $T H$ が $0.35 \mu \mathrm{m}$ では主磁極中心で負の磁界が大 きくなっており, その結果残留磁界強度が最も小さくなっている.

\section{2 多層膜主磁極における磁界強度の層数依存性}

次に単層主磁極のシミュレーションにて最も大きな記録磁界が 得られた $T H: 0.25 \mu \mathrm{m}$ のSPT 垂直ライトヘッドについて主磁極 を多層化した場合の記録および残留磁界強度について議論する.

Fig. 4 は主磁極として反強磁生結合多層膜を想定し, 全膜厚を 260

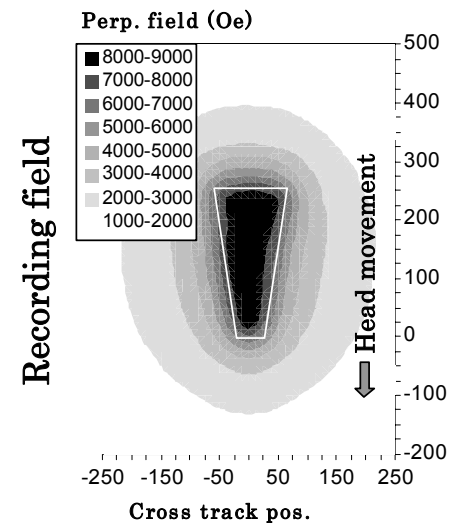

(a) Single layer

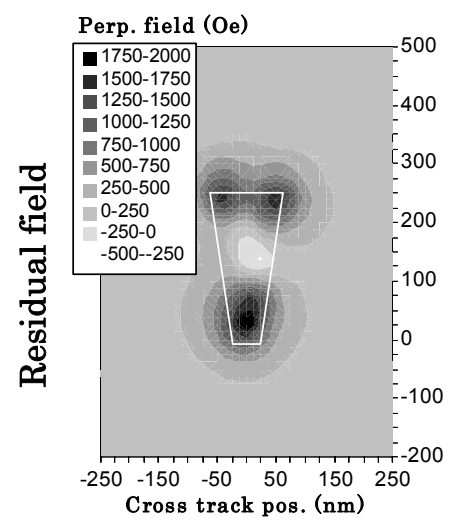

(e) Single layer

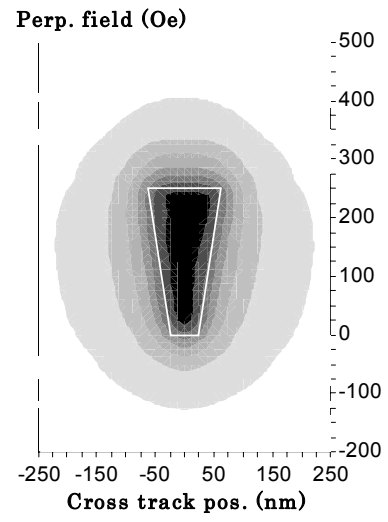

(b) 2 layers

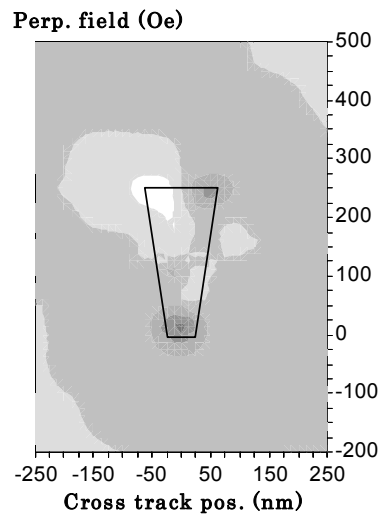

(f) 2 layers

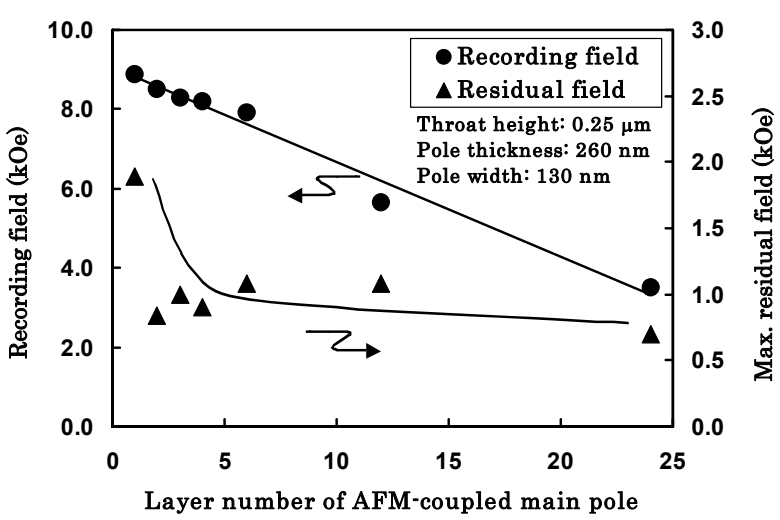

Fig. 4 Recording and residual field strength dependence on layer number of AFM-coupled multilayer main pole.

$\mathrm{nm}$ に固定したまま層数を変化した場合のヘッド発生磁界の変化 である. 図から明らかなように層数を多くすると記録磁界強度は 単調减少寸る. 一方, 残留磁界強度については層数を単層から 2 層にすることで約半減し, 2 層以上では残留磁界強度の変化がほぼ 無く, 1000 Oe 以下の小さな值を保つ. 残留磁界強度は多層膜の 層数を増加することで減少傾向にあるものの、その変化は磁気特 性、磁極形状、その他の条件に左右されるため記録磁界のような

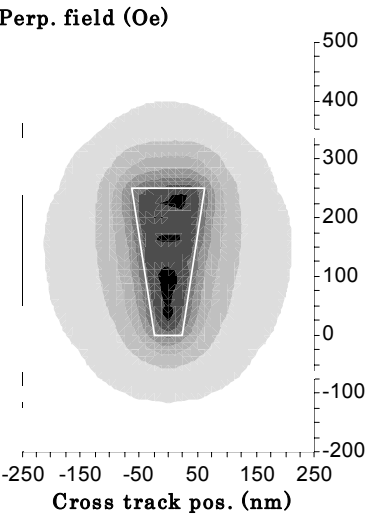

(c) 4 layers

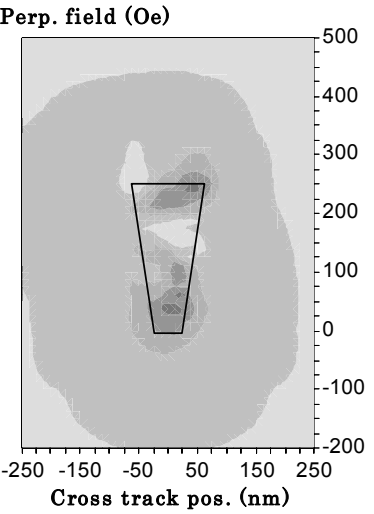

(g) 4 layers

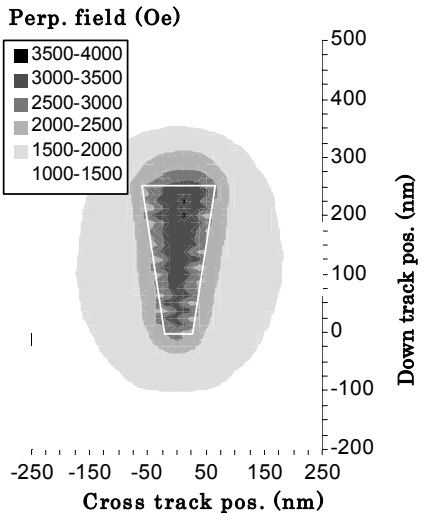

(d) 24 layers

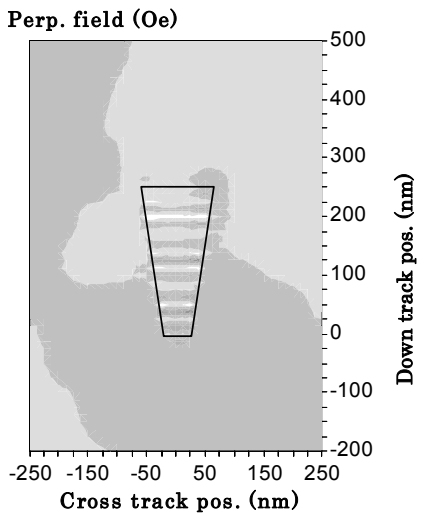

(h) 24 layers

Fig. 5 Head field distributions of STP writer head with different layer structure main pole. (a) to (d) are recording head field and (e) to (f) are residual head field distributions. 


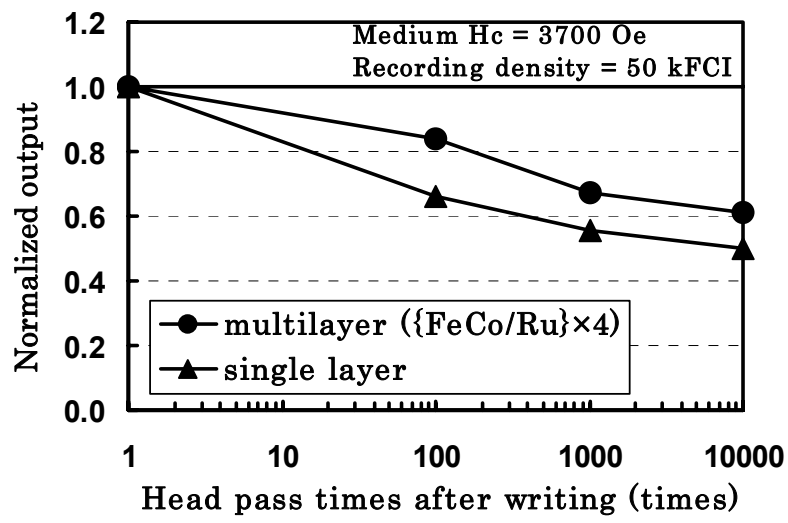

Fig. 6 Experimental pole-erase evaluations with single and multilayer SPT writer head.

単調な変化ではなく複雑な挙動を示す。Fig. 5 に単層および 2,4 , 24 層の記録およひ残留磁界の二次元分布図を示寸. 24 層の反強磁 性結合多層膜を主磁極とした場合，各層間の反強磁性結合が強い ためライト通電時（0.15 AT 起磁力印加時）においても主磁極の 磁化方向が一方向に揃わない.このため記録磁界強度としては $3500 \mathrm{Oe}$ と小さく十分な O/W 性を確保することが困難であると予 想される. なお，磁界強度については Fig. 4 も併せて参照された い. 全体を 4 層に分割した場合にも反強磁生結合の影響のため記 録磁界の強弱が存在するが，記録磁界強度としては 8200 Oe を確 保しており，単層主磁極へッドの $8900 \mathrm{Oe}$ には若干劣るものの比 較的大きな記録磁界強度を確保している.

一方残留磁界強度について比較すると, 単層ヘッドでは主磁極 のトレーリングおよびリーディング エッジから 2000 Oe 弱の残 留磁界が発生しており, ポールイレーズが看念される. 主磁極を 2 層以上の反強磁生結合多層膜とすることで残留磁界は半減され, 1000 Oe 以下の残留磁界強度となる．以上の結果から記録および 残留磁界強度の両者を考慮すると, 反強磁生結合多層膜を STP 垂 直ライトヘッドの主磁極材料として適用する場合, $2 \sim 4$ 層程度の 多層化とすることで比較的大きな記録磁界と，小さな残留磁界が 得られる.

\section{5. ポールイレーズ実測結果との比較}

Fig. 6 に単層および反強磁生結合多層膜を主磁極材料として適 用した SPT ライトヘッド7のポールイレーズ量の実測評価結果を 示す．主磁極の材料は $\mathrm{FeCo}$ および $\{\mathrm{FeCo} / \mathrm{Ru}\} \times 4$ 層を用いた. いずれのヘッドも主磁極の全膜厚を $280 \mathrm{~nm}$ ，トレーリング側の光 学トラック幅を $120 \mathrm{~nm}$ として作製した。 ポールイレーズの評価 は AC バンドイレーズ後，50kFCI の信号を 1 周記録し，その後 ヘッドをオントラックのまま放置し，100，1000，10000 周後の ヘッド出力を読み取り，各出力を記録直後のヘッド出力で規格化 してイレーズ量を求めた. なお, 評価に当たっては, $H_{C} / H n: 3700$
/ $1400 \mathrm{O}$ 程度, 角形比はほぼ 1 , 記録層膜厚: $6 \mathrm{~nm}$ の比較的イレ 一ズの起こりやすい媒体を用いて相対評価を行った. 主磁極材料 を $\{\mathrm{FeCo} / \mathrm{Ru}\} \times 4$ 層の多層膜とすることで, $\mathrm{FeCo}$ 単層膜に比較し てポールイレーズ量が減少することを実測においても確認した. また，O/W 性についても両へッドでほぼ同等の特性が得られ，シ ミュレーション結果と一致した.

\section{6. まとめ}

単磁極垂直ライトヘッドの一つの問題点であるポールイレーズ 対策として, 主磁極への反強磁生結合多層膜の適用およびその膜 厚最適化について計算機シミュレーションを用いて検討を行った. 反強磁生多層膜主磁極のモデル化およびポールイレーズ(残留磁界 強度)のシミュレーションにあたり, LLG と FEM を組み合わせた 連成シミュレータを新たに開発した. 同シミュレータを用いた解 析の結果, 記録磁界強度は多層膜の層数を多くすると単調减少し, 残留磁界強度は層数を 2 層以上とすることで急激に減少すること を明らかにした．以上から垂直ライトヘッドの主磁極材料として 反強磁性結合多層膜を適用する場合, 層数を $2 \sim 4$ 層程度にする ことで記録・残留磁界強度を両立させることができる．また，実 ヘッドによるポールイレーズ量の実測においても同傾向を確認し た.

\section{References}

1) S. Iwasaki and Y. Nakamura: IEEE Trans. Magn., 1(13), 1272 (1977).

2) H. N. Bertram and M. Williams: IEEE Trans. Magn., 36(1), 4 (2000).

3) M. Mallary, A. Torabi, and M. Benakli: IEEE Trans. Magn. 38(4), 1719 (2004).

4) W. Cain, A.Payne, M. Baldwinson, and R. Hempstead: IEEE Trans. Magn., 32(1), 97 (1996).

5) B. M. Lairson, S. R. Lambert, L. Nguyen, A. Wallash, T. Huang, and J. Adler: IEEE Trans. Magn., 37(4), 1223 (2001).

6) K. Nakamoto, T. Okada, K. Watanabe, H. Hoshiya, N. Yoshida, Y. Kawato, M. Hatatani, K. Meguro, Y. Okada, H. Kimura, M. Mochizuki, K. Kusukawa, C. Ishikawa, and M. Fuyama: IEEE Trans. Magn., 40(1), 290 (2004).

7) Y. Ikegawa, S. Yamawaki, N. Ozaki, T. Hoshino, T. Kubomiya, K. Satoh, and T. Kosikawa: IEEE Trans. Magn., 40(4), 2338 (2004).

8) D. Z. Bai and J.-G. Zhu: IEEE Trans. Magn., 38(5), 2240 (2002).

9) M. Mochizuki, C. Ishikawa, H. Ide, K. Nakamoto, Y. Nakatani, and N. Hayashi: J Appl. Phys., 93(10), 6748 (2003).

10) Y. Kanai and R. Matsubara: IEEE Trans. Magn., 38(1), 169 (2002).

11) W. Xia, H. Muraoka, and Y. Nakamura: IEEE Trans. Magn., 38(5), 2216 (2002).

12) K. Shimizu, H. Akimoto, and A. Tamura: FUJITSU Magazine, 55(3), 238 (2004).

2004 年 10 月 8 日受理, 2005 年 2 月 8 日採録 